\title{
Adverse effects of beta-blockade withdrawal in patients with congestive cardiomyopathy
}

\author{
K SWEDBERG, Å HJALMARSON, F WAAGSTEIN, I WALLENTIN \\ From the Departments of Medicine I and Clinical Physiology, Sahlgren's Hospital, University of Göteborg, \\ Göteborg, Sweden
}

SUMMARY Fifteen patients with congestive cardiomyopathy who had improved conspicuously on chronic administration of a beta-blocker were studied after withdrawal of the drug. In six patients there was a pronounced deterioration of their clinical condition, and in all of the remaining patients there was a significant decrease in ejection fraction, and signs of compromised diastolic function with pathological apex curves and an increase in third heart sound. All these changes were reversed within a few weeks to a few months after readministration of beta-blocking drugs. This study supports the idea that an aetiological factor in congestive cardiomyopathy may be a pathological response to sympathetic stimulation which could be partly controlled by administration of beta-blocking drugs.

An improvement in myocardial function and general condition with chronic beta-blockade in patients with congestive cardiomyopathy (COCM) was first reported in $1975,{ }^{1}$ and this has been confirmed in a more extensive recent study. ${ }^{2}{ }^{3}$ It has been known for many years that in patients with heart failure there is a compensatory increase in sympathetic nervous activity to counteract the depressed myocardial function. ${ }^{4}$ Furthermore, betablockade is thought to aggravate heart failure and this treatment is said to be contraindicated in such patients. Taking this into account, the finding that beta-blocking agents could cause an improvement in myocardial function in patients with congestive cardiomyopathy and heart failure was surprising and unexpected.

In this study beta-blockade was withdrawn in patients with COCM after long-term administration. This was done for two reasons. First, the effects of withdrawal should give useful information about the role of beta-blockade in the improvement in myocardial function after long-term treatment. Second, valuable information could be obtained about the mechanisms underlying the observed beneficial effect of beta-blockade in these patients. Would there be an immediate deterioration in the patients' condition in parallel with the fall in tissue concentration of the beta-blocking agent? Would the improved myocardial function persist even without beta-blockade, indicating that the treatment Received for publication 13 August 1979 had been curative and not merely functioning by modulating heart rate and pressure development?

\section{Patients and methods}

In January 1978, 19 patients with congestive cardiomyopathy who had undergone chronic betablockade for at least six months were considered for the withdrawal study. Two patients who had been on beta-blockers for four-and-a-quarter and five years refused to discontinue the treatment. One patient was living far from Göteborg and could not take part in a closely controlled study. One patient had recently required an increase in metoprolol dosage to counteract a deterioration in cardiac function and it was therefore judged unethical to discontinue treatment. The remaining 15 patients were informed about the study and agreed to take part.

The duration of treatment and the daily dose of a beta-blocking agent before withdrawal are shown in the Table. All patients had taken the same dose of metoprolol for at least one month before investigation. Treatment with digitalis and diuretics continued unchanged. The patients were assessed (see below) at least once weekly during the first month after withdrawal of beta-blockade. If changes in their general condition or signs of progressive heart failure appeared, they were reassessed immediately. In patients with no subjective or objective changes after beta-blockade, withdrawal 
reassessment was performed after four months. The investigations performed at each assessment included phonocardiograms from five standard areas, an apex cardiogram, pulse tracings from the carotid artery, jugular vein, and liver, and an echocardiogram, as described elsewhere. ${ }^{3}$

One patient (case 1) discontinued treatment, without our knowledge, in January 1978 after four years as he had been without symptoms of heart failure for three years. He was included in the study and reassessed in April 1978 at which time he showed deterioration in cardiac function, with symptoms of heart failure. He was again given metoprolol and was reassessed 29 days after restart of treatment. All investigated variables and his general condition were compared with the previous findings of June 1976. These findings are included with the prewithdrawal data of the other patients. Two patients stopped their treatment after the toxic effects of practolol were reported in 1975. The clinical findings in these patients are also reported.

\section{Results}

The duration of treatment before withdrawal, and the length of the observation period after withdrawal of beta-blockade are given for all patients in the Table. This also contains the assessment of the patients after withdrawal of the drug. The patients were observed after withdrawal for seven to 119 days (mean 72 days) before treatment was restarted. Six patients showed a clear deterioration in their clinical condition, with signs of increased heart failure. Two of these patients (cases 6 and 28) deteriorated very rapidly with a return of dyspnoea, hypotension, poor peripheral circulation, and loud third and fourth heart sounds within 14 days. Case 1 had received treatment for $\mathbf{4 8}$ months and returned to his poor pre-beta-blockade condition within two months of withdrawal. Case 16 complained after three weeks and was reinvestigated after 27 days. No significant abnormalities were found, and he continued without beta-blockade. He died suddenly two weeks later.

\section{Case reports}

\section{CASE 1}

This male patient was previously healthy except for recurrent duodenal ulceration treated by gastric resection at the age of 40 . At the age of 53 congestive cardiomyopathy was diagnosed when moderate biventricular failure developed in connection with an upper respiratory tract infection. Over the next 18 months, he showed a progressive deterioration in cardiac function, and at the end of this period was considered to be in functional group IV (NYHA classification). Haemodynamic investigations showed a cardiac index of $1.051 / \mathrm{min}$ per $\mathrm{m}^{2}$ and a left ventricular end-diastolic pressure (LVEDP) of $22 \mathrm{mmHg}$; the left ventricular enddiastolic diameter (LVEDD) was $6.2 \mathrm{~cm}$ and the ejection fraction (EF) 0.22 measured echocardiographically (Fig. 1a-e). Practolol was given initially in a very low dosage. Eventually practolol, $100 \mathrm{mg}$ twice daily, was well tolerated and the patient's condition dramatically improved over two months. Reinvestigation showed an increase in the cardiac index to $2.91 / \mathrm{min}$ per $\mathrm{m}^{2}$, normalisation of the

Table Cardiovascular effects of withdrawal of chronic beta-blockade in patients with congestive cardiomyopathy

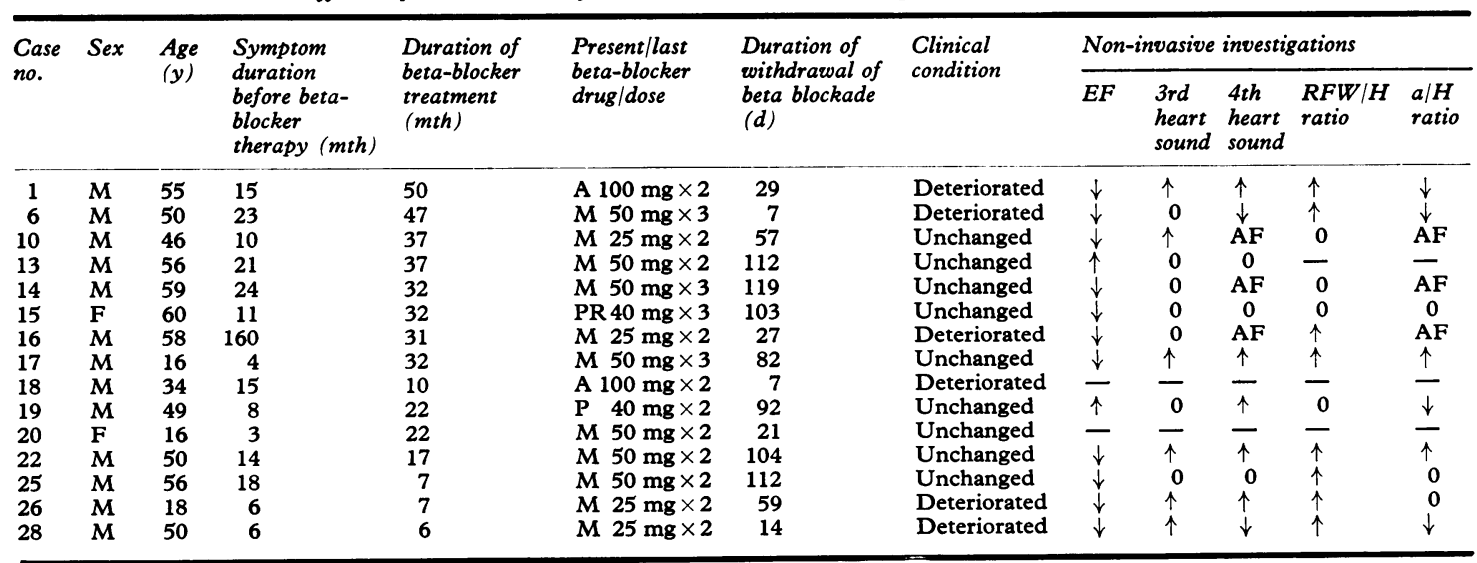

A, alprenolol; M, metoprolol; P, practolol; PR, propranolol; EF, ejection fraction; RFW/H ratio, rapid filling wave ratio; a/H ratio, "a" wave ratio; 0 , unchanged; $\uparrow$, increased; $\downarrow$, decreased; -, not investigated; AF, atrial fibrillation. 
resting LVEDP, and a reduction of the exercise LVEDP; the EF had increased to 0.58 and the LVEDD had decreased to $4.8 \mathrm{~cm}$ (Fig. 2). During the next two years the patient continued to improve, after which he defaulted from follow-up. Eighteen months later he was readmitted in severe biventricular failure, which had developed two months after accidental withdrawal of alprenolol. Again, the echocardiographic findings were grossly abnormal (Fig. 3) with an LVEDD of $6.7 \mathrm{~cm}$, an EF of 0.23 , and signs of mitral regurgitation. The findings were similar to those noted before betablockade was instituted. Metoprolol was given in low dosage and was well tolerated. Clinical improve- ment was obvious within two months of the start of treatment and continued for the next year. Reinvestigation confirmed the clinical improvement (Fig. 4), with a reduction in LVEDD to $4.7 \mathrm{~cm}$ and an increase in EF to 0.59.

\section{CASE 2 (CASE 16 IN TABLE)}

This male patient had previously been healthy except for diphtheria at the age of 7 . At the age of 42, he developed moderate exertional dyspnoea and was considered to be in functional group II. Moderate cardiomegaly was noted on $x$-ray film. At the age of 58 he suddenly developed severe cardiac failure with pronounced cardiomegaly
Fig. 1a-e Non-invasive findings in case 1 during treatment with digitalis and diuretics

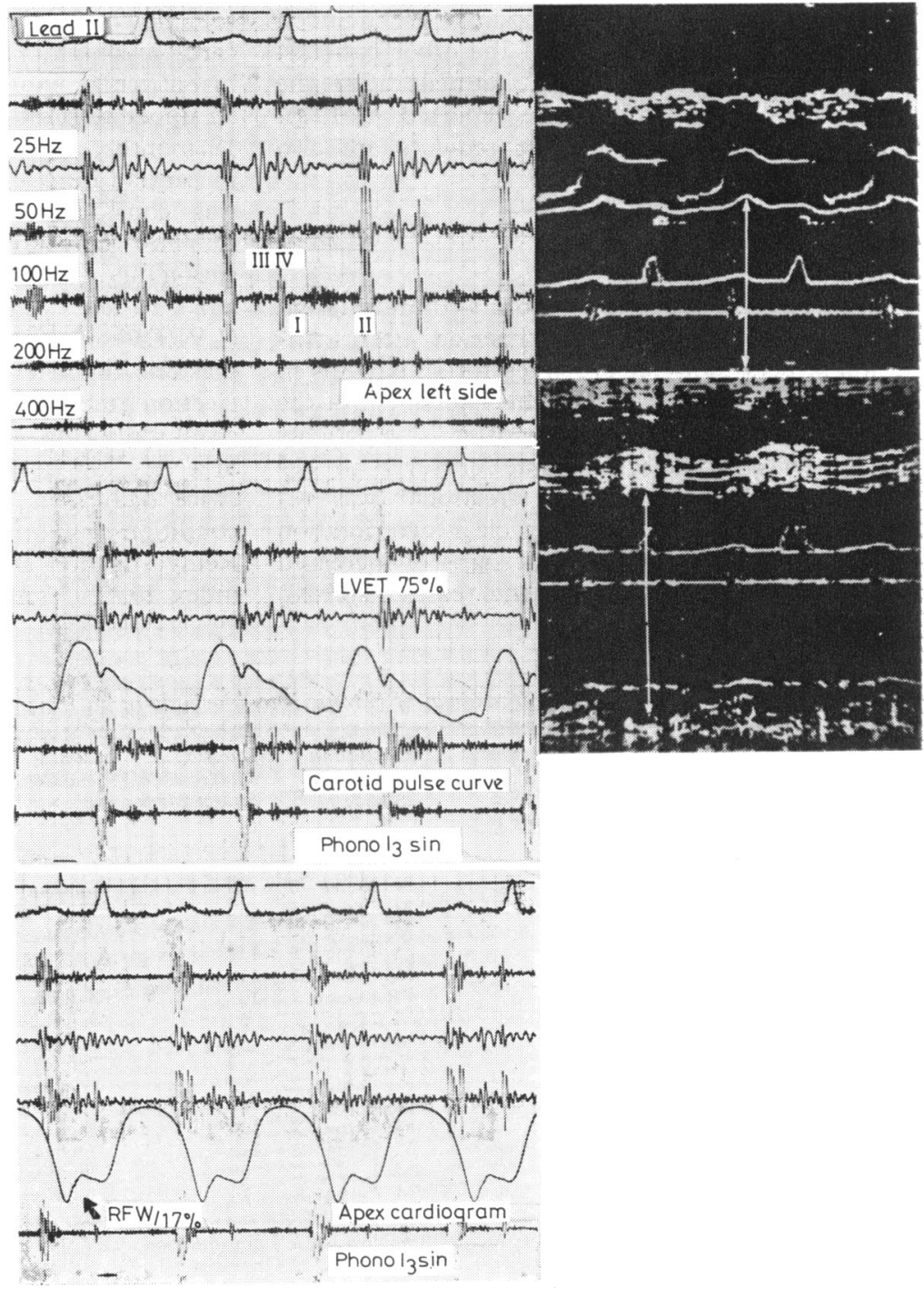


( $800 \mathrm{ml} / \mathrm{m}^{2}$ bsa, measured radiographically). The echocardiograph showed a dilated left ventricle with an LVEDD of $7.0 \mathrm{~cm}$ and a moderately reduced EF of 0.50. A loud third heart sound and an apical systolic murmur were also present.

As he was in functional group III, he was given placebo according to the study procedure. Over the next three months, however, his functional status deteriorated to group IV, and beta-blockade was therefore instituted. Over the following year his clinical condition steadily improved with a distinct increase in exercise tolerance, a slight increase in EF to 0.60 , and virtual disappearance of the third heart sound. There was, however, no change in heart size or LVEDD. He returned to full-time work and at this time was considered to be in functional group II. After 30 months on active treatment this was withdrawn according to the study procedure. After two weeks the patient began to experience exertional dyspnoea on moderate exercise, and a moderate reduction of the ejection fraction to 0.50 and a decreased left ventricular ejection time (LVET) were shown by echocardiograph and carotid pulse respectively. As the changes were only moderate, the withdrawal phase of the study was continued. Three weeks later, however, the patient died suddenly without an increase of cardiac symptoms. Cardiac arrhythmias
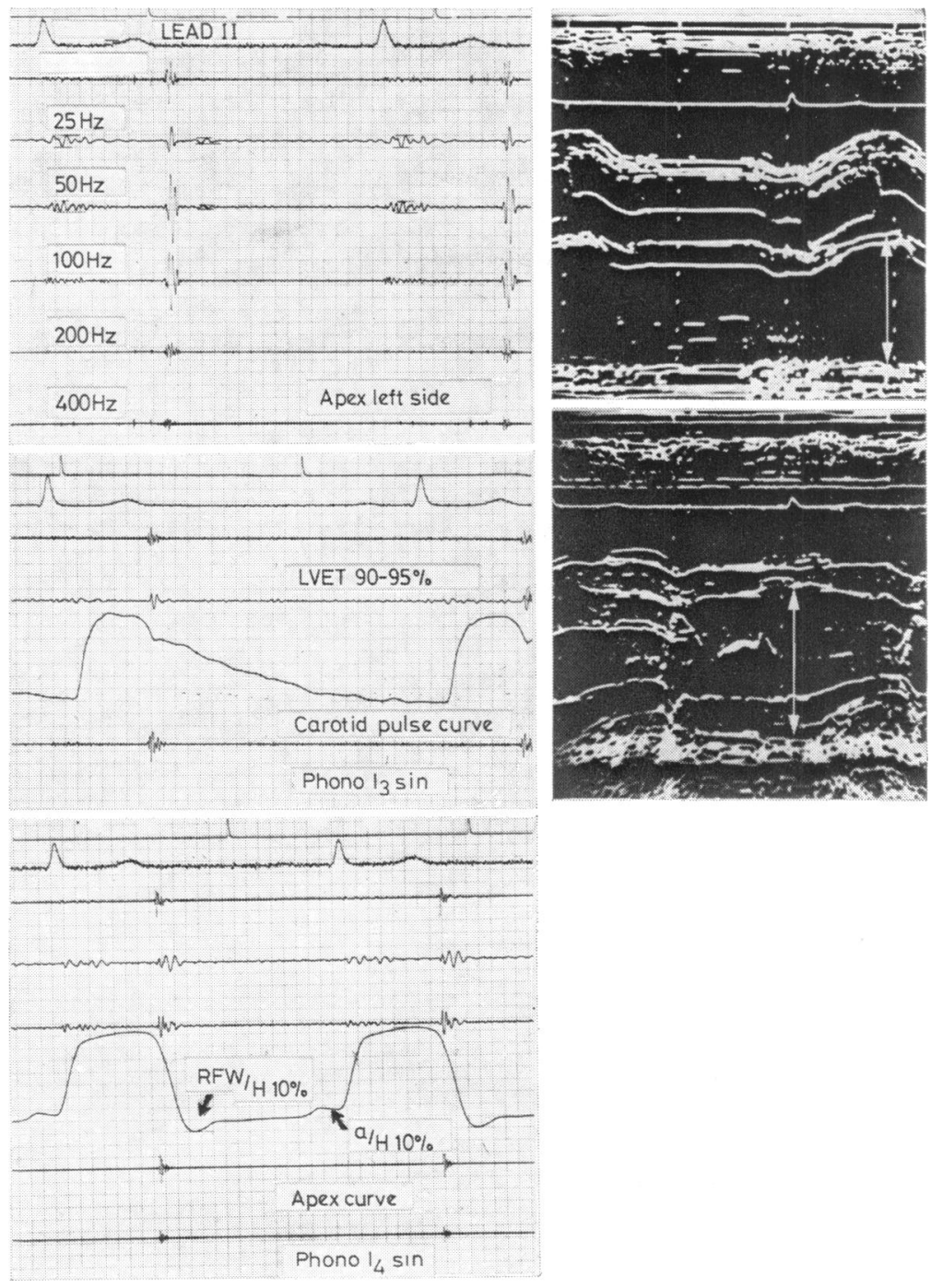

Fig. 2a-e Non-invasive findings in case 1 during treatment with chronic beta-blockade 
were considered to be the immediate cause of death. At necropsy the patient was found to have a grossly dilated heart with pulmonary congestion.

\section{CASE 3 (CASE 28 IN TABLE)}

This male patient, previously healthy except for pulmonary tuberculosis controlled by chemotherapy, had suddenly developed biventricular cardiac failure six months before the start of beta-blockade. His condition deteriorated progressively despite treatment with digoxin and frusemide, and his functional grade was IV when he was considered for inclusion in the study.

Haemodynamic investigations at this time showed a cardiac index of $1.21 / \mathrm{min}$ per $\mathrm{m}^{2}$, and a grossly dilated left ventricle with an LVEDD of $8.0 \mathrm{~cm}$ and an EF of 0.18 were shown echocardiographically. A loud third heart sound was present and was recorded on the phonocardiogram. Metoprolol was given initially in very low dosage. This was eventually increased to $25 \mathrm{mg}$ twice daily which was well tolerated and the patient's condition improved with an increase in exercise capacity. The third heart sound decreased considerably. The EF increased to 0.42 , but the LVEDD decreased only slightly to $7 \cdot 2 \mathrm{~cm}$. According to the study procedure, active treatment was withdrawn after six months and the patient carefully supervised in
Fig. 3a-e Non-invasive findings in case 1 after two months of withdrawal of beta-blockade.

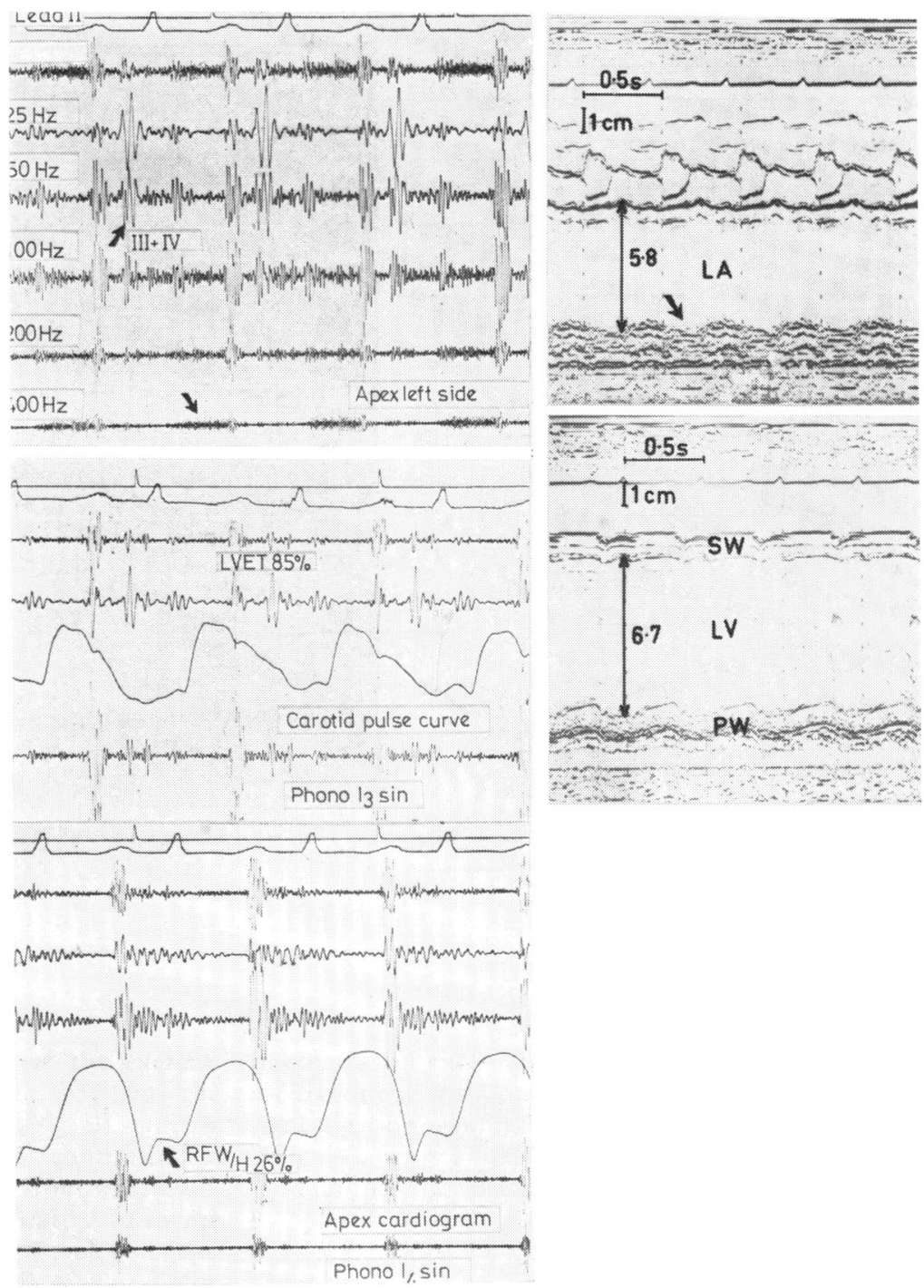


hospital for a period of five days. During this time there was no change in the patient's clinical condition though the third heart sound reappeared. Nine days after discharge he was readmitted semiconscious in cardiogenic shock with mechanical alternans and a systolic blood pressure of 50 to $60 \mathrm{mmHg}$. Echocardiography confirmed the clinical impression of much depressed myocardial systolic function, the EF being 0.22 and the LVEDD $7.5 \mathrm{~cm}$. A very loud third heart sound was again present. Attempts to reintroduce beta-blockade were unsuccessful, but the patient responded to intravenous therapy with prenalterol, a new selective beta $_{1}$-agonist $^{56}$ given over 48 hours. After this, metoprolol was successfully reintroduced, and the patient's clinical condition and findings on investigation improved to their previous levels within two months.

\section{Investigations}

All patient data are summarised in Fig. 5-7. One patient was studied for only 21 days and no reinvestigation was performed as she had to go
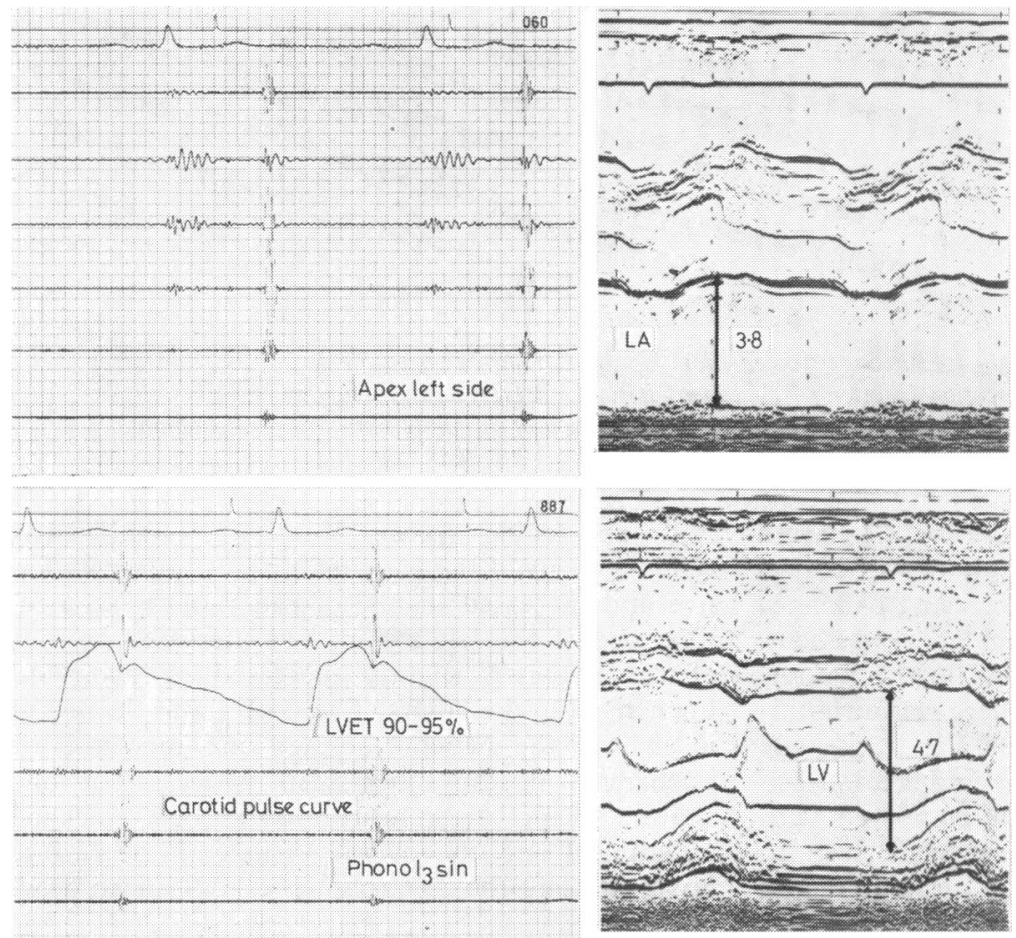

Fig. 4a-e Non-invasive findings in case 1 one year after betablockade was restarted. Phono $I_{3} \sin =$ phonocardiogram from left third intercostal space.

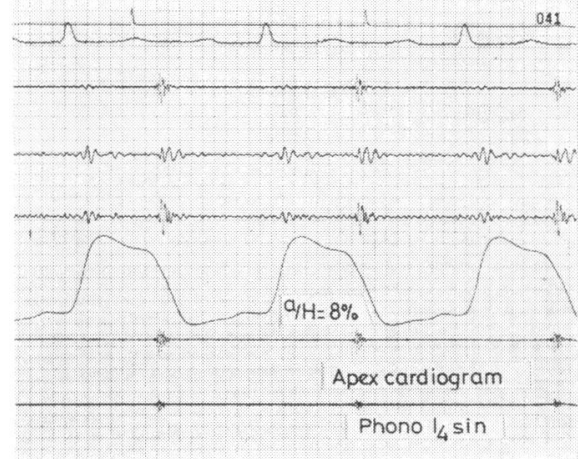




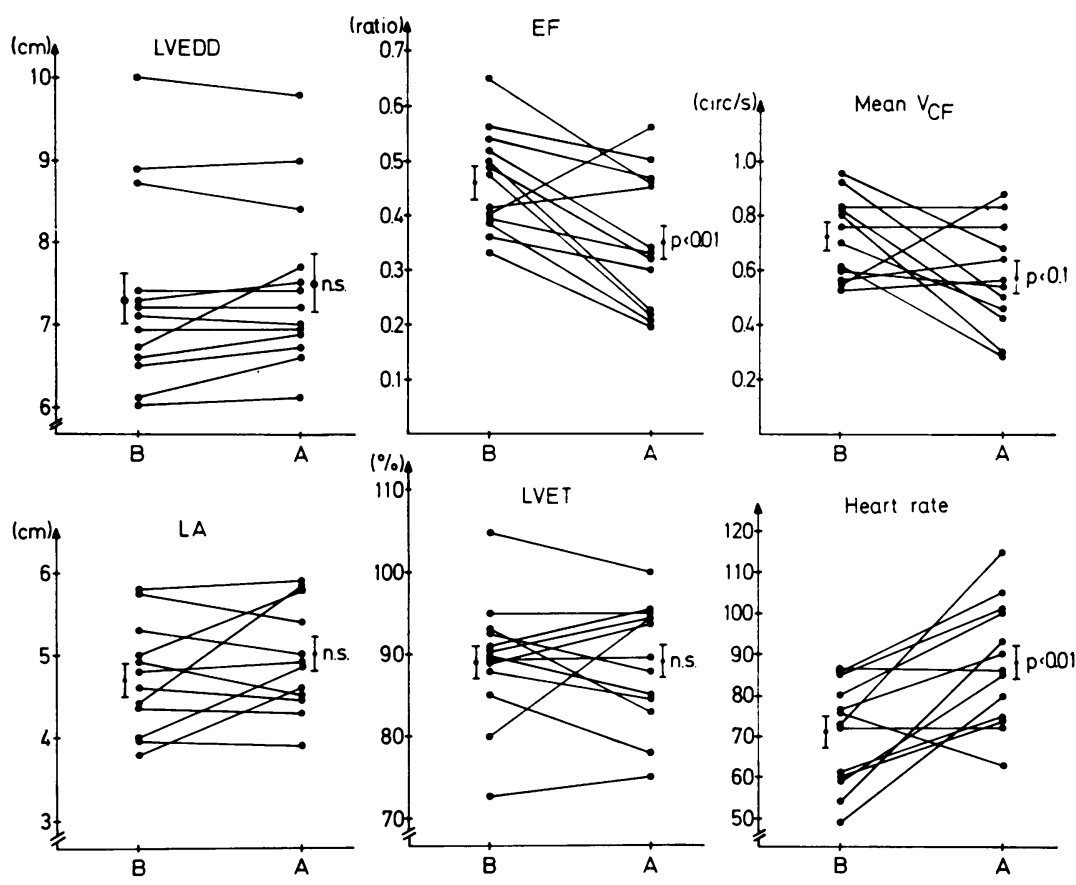

Fig. 5 Non-invasive findings in patients with congestive cardiomyopathy on chronic beta-blockade $(B)$ and after withdrawal of treatment $(A)$. EF, ejection fraction; $L A$, left atrium; $L V E D D$, left ventricular end-diastolic diameter; $L V E T$, left ventricular ejection time; Mean $V_{C F}$, mean velcocity of circumferential fibre shortening.

abroad (case 20). Another patient (case 18) started alprenolol treatment after seven days of withdrawal without our notice because of increasing dyspnoea and it was not possible to obtain an assessment. The other 13 patients are included in the figures. From Fig. 5 it can be seen that there was a significant fall in the EF from $0.46 \pm 0.03$ to $0.35 \pm 0.03$ $(p<0.01)$, all but two patients having a lower EF after withdrawal of beta-blockade compared with before its withdrawal. No changes were seen in LVEDD. The mean velocity of circumferential fibre shortening (mean $V_{C F}$ ) was significantly reduced in six of the patients but was unchanged in five and increased in one of the patients studied. The size of the left atrium was increased in four of the patients, slightly increased in two, and unchanged in the others. The LVET was decreased in half of the patients studied and increased or unchanged in the others. All patients but one showed an increase in heart rate after beta-blockade withdrawal and the overall change in heart rate was significant for the group ( $p<0.01)$ (mean heart
Fig. 6 Amplitude of third and fourth heart sounds in patients with congestive cardiomyopathy before ( $S$ ) and during ( $B$ ) beta-blocker treatment, and after (A) withdrawal of the drug.
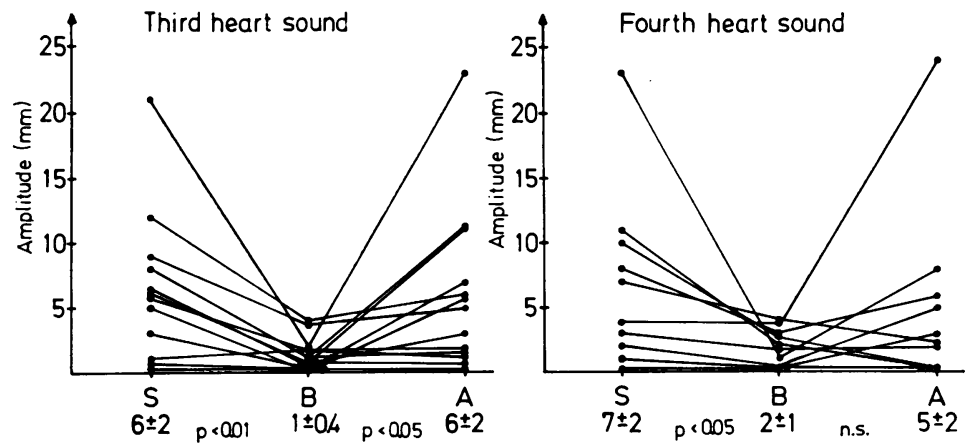
rate $71 \pm 3$ on beta-blockade; $88 \pm 4$ beats per minute after withdrawal).

The recorded amplitude of the third heart sound increased from $1 \pm 0.4$ to $6 \pm 2 \mathrm{~mm}(\mathrm{p}<0.05)$ and was much increased in seven of the patients (Fig. 6). Seven of the patients had no measurable third heart sound on beta-blockade and it returned in five of these patients after discontinuation of treatment. Though several of the patients also showed an increase in the fourth heart sound amplitude, the changes in this index were more variable.

The changes in RFW/H ratio are shown in Fig. 7. A significant increase in RFW occurred $(\mathrm{p}<0.05)$ and all but two of the patients studied showed an individual increase. Changes in $\mathrm{a} / \mathrm{H}$ ratio increased in some patients and decreased in others so that the mean value for the group was not changed with withdrawal of beta-blockade. Three of the patients showing a reduction in the " $a$ " wave (cases 1, 6, and 28) had a clear increase in RFW.

During long-term treatment with beta-blockade two patients who had been on beta-blockade for 24 months and 12 months discontinued treatment without informing us. This was done by one (case 5) when the toxic effects of practolol were reported, and by the other (case 6 ) because of persisting exertional dyspnoea. After discontinuation of betablockade both developed severe cardiac failure and were brought to hospital with pulmonary oedema. When beta-blockade was reinstituted there were no further attacks of pulmonary oedema in either of them.

\section{Discussion}

The present study shows that myocardial function in congestive cardiomyopathy can be impaired by withdrawal of beta-blockers. Six of the 15 patients in the study showed a distinct deterioration in their clinical condition, with the appearance of increased dyspnoea, and three of the patients showed other signs of severe cardiac failure; such as hypotension, poor peripheral circulation, and cardiogenic shock. One of the patients who developed increased dyspnoea died suddenly 41 days after beta-blockade was discontinued. Cardiogenic shock developed two weeks after withdrawal in another patient. The ejection fraction, as measured from the echocardiogram, was decreased in 11 of the 13 patients in whom it was measured. Eight patients showed an increase in rapid filling wave and six patients a clear increase in the amplitude of the third heart sound. It appeared that the patients who had had the most dramatic improvement with beta-blockade showed the most severe deterioration after its withdrawal. The development of pulmonary oedema in the two patients who stopped treatment without our knowledge is in accord with the other observations following planned beta-blockade withdrawal. The results from this study strongly support the findings of
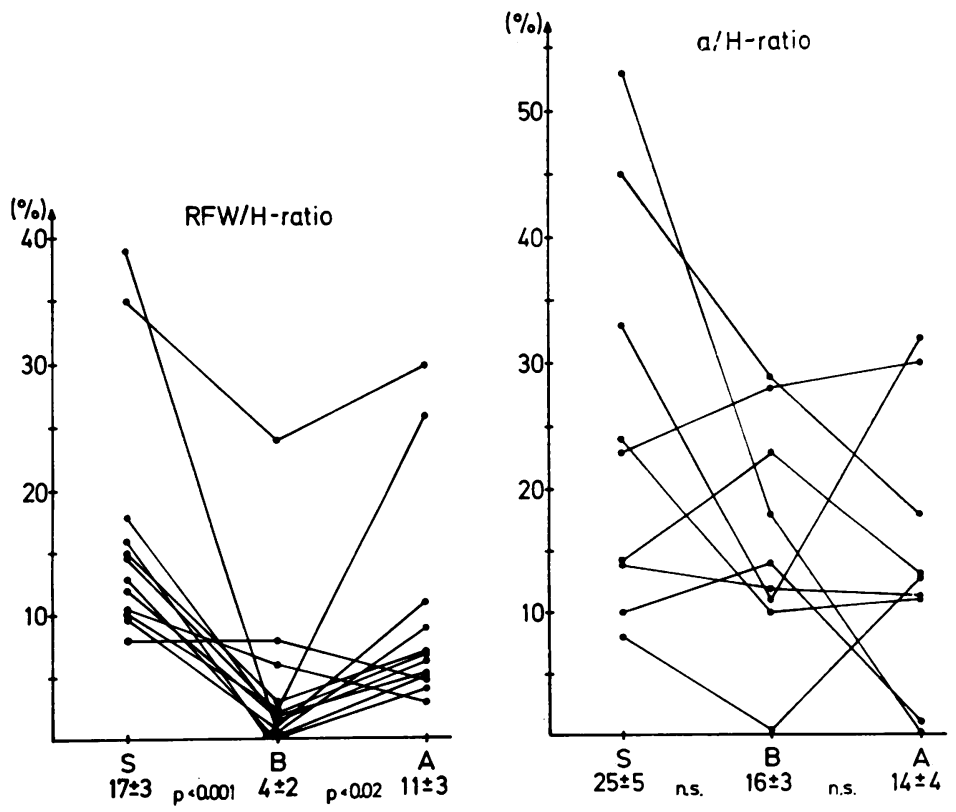

Fig. 7 Rapid filling wave ratio ( $R F W \mid H$ ratio) and " $a$ " wave ratio (a/H ratio) in patients with congestive cardiomyopathy before (S) and during (B) betablocker treatment and after (A.) withdrawal of the drug. 
improved clinical condition and myocardial function with chronic beta-blockade, as reported before. ${ }^{1-3}$

A deterioration in myocardial function after discontinuation of chronic beta-blockade indicates that the treatment has not been curative. In the patients whose clinical condition deteriorated with the appearance of severe dyspnoea this appeared in two of them very soon after discontinuation of betablockade while there was a slower deterioration in the others. This suggests that impaired cardiac function does not correlate directly with the fall in tissue drug concentration in all patients. Betablockade, by reducing heart rate and myocardial work, could have beneficial effects on energy metabolism and heart function. The reduction of metabolic demand induced by beta-blockade would be beneficial if the myopathic heart cells were deficient in energy-yielding substrates, such as ATP, and at risk of accumulation of metabolites, such as lactate and $\mathrm{NADH}^{+}$. Metabolic overactivity in the myopathic cells could be caused by inappropriately high sympathetic activity or increased sensitivity of the cells to sympathetic stimulation. The delayed clinical deterioration in some patients could be related to structural changes within the myopathic heart cells in the absence of the protective effects of beta-blockade. It is known that catecholamines have a direct stimulatory effect on processes of protein synthesis in the heart, and it has been suggested that the synthesis of a defective contractile protein could be a consequence of increased sensitivity to beta ${ }_{1}$-stimulation. ${ }^{7}$ It seems unlikely that a rebound phenomenon after withdrawal of beta-blockade was of importance in this study. In dogs, haemodynamic and metabolic responses to abrupt withdrawal of beta-blockade usually appear within 24 to 48 hours, ${ }^{8}$ and in man it has been reported that the greatest sensitivity to catecholamines after withdrawal of long-term betablockade occurs within four to six days. ${ }^{9}$ Symptoms such as chest pain and ventricular arrhythmias in patients with ischaemic heart disease have been reported as occurring immediately after chronic treatment is stopped. ${ }^{10}$

In conclusion, the present study strongly supports the hypothesis that sympathetic nervous activity, in some way, plays a role in the development of congestive cardiomyopathy. Any group of patients with congestive cardiomyopathy is heterogeneous and the role of catecholamines in the development of the disease and the appearance of symptoms may be variable. Chronic beta-blockade will produce clinical improvement in some patients but not in others. ${ }^{3}$ Similarly, withdrawal of beta-blockade caused a distinct deterioration in some of the patients in this study, but had little influence on the others.

This investigation was supported by grants from the Swedish National Association against Heart and Chest Diseases, the Faculty of Medicine, University of Göteborg, and the Göteborg Medical Society, Sweden.

\section{References}

${ }^{1}$ Waagstein F, Hjalmarson $\AA$, Varnauskas E, Wallentin I. Effect of chronic beta-adrenergic receptor blockade in congestive cardiomyopathy. Br Heart $\mathcal{F}$ 1975; 37: 1022-36.

${ }^{2}$ Swedberg K, Hjalmarson $\AA$, Waagstein F, Wallentin I. Prolongation of survival in congestive cardiomyopathy by beta-receptor blockade. Lancet 1979; 1: 1374-6.

${ }^{3}$ Swedberg K, Hjalmarson $\AA$, Waagstein F, Wallentin I. Beneficial effects of long-term beta-blockade in congestive cardiomyopathy. $\mathrm{Br}$ Heart $\mathcal{f} 1980 ; 44$ : $117-33$.

${ }^{4}$ Chidsey CA, Braunwald E, Morrow AG. Catecholamine excretion and cardiac stores of norepinephrine in congestive heart failure. Am $\mathcal{F}$ Med 1965; 39: 442-51. ${ }^{5}$ Johnsson G, Jordö L, Lundborg P, Rönn O, WelinFogelberg I, Wikstrand J. Haemodynamic and tolerance studies in man with a new, orally active, selective beta $_{1}$-adrenoceptor agonist $\mathrm{H} 80 / 62$. Eur $\mathcal{f}$ Clin Pharmacol 1978; 13: 163-70.

'Ariniego R, Waagstein F, Mombay B, Hjalmarson A. Haemodynamic effects of a new $\beta_{1}$-receptor agonist in acute myocardial infarction. A useful antidote to unwanted cardiac effects of $\beta$-blocking agents. $B r$ Heart f 1979; 42: 139-46.

${ }^{\prime}$ Källfelt BJ, Hjalmarson AC, Isaksson OG. In vitro effects of catecholamines on protein synthesis in perfused rat heart. $\mathcal{F}$ Mol Cell Cardiol 1976; 8: 787-802.

${ }^{8}$ Myers JH, Horwitz CD. Hemodynamic and metabolic response after abrupt withdrawal of propranolol. Circulation 1978; 58: 196-201.

'Nattel S, Rangno RE, van Loon G. Mechanism of propranolol withdrawal phenomena. Circulation 1979; 59: $1158-64$.

${ }^{10}$ Miller RR, Olson HG, Amsterdam EA, Mason DT. Propranolol-withdrawal rebound phenomenon. Exacerbation of coronary events after abrupt cessation of antianginal therapy. $N$ Engl f Med 1975; 293: 416-8.

Requests for reprints to Dr Karl Swedberg, Department of Medicine, East Hospital, S-416 85 Göteborg, Sweden. 